\title{
Seismic Design
}

\section{Considerations for}

\section{Architectural Design}

\section{Aspects}

Serra Zerrin Korkmaz*

\section{Abstract}

Architectural design decisions play an important role in the earthquake behavior of buildings. However, architects are very unfamiliar with earthquake response concept. Earthquake resistant design (ERD) initiates generally during the architectural design stage to adhere to these principles. This study was focused on plan geometries, architectural design and structural system configurations for structural earthquake responses. A general-purpose finite element program was used to evaluate several irregularities and their corresponding earthquake responses. In the first phase of the study, the projections in plan view and projection ratios were compared from a torsional response perspective. In the second phase, nonparallel axes are investigated. In the last phase, the effects of shear wall arrangement on torsional irregularity response were analysed by considering 4 different configurations in a school building failure during the recent earthquake (2011) in the city, Van located in the east of Turkey. The number of storys was chosen as a parameter for the latter phase. The mode superposition method was preferred for the linear dynamic analyses. According to the results of the study, the torsional rotation was found to be proportional
Keywords: Earthquake, irregularity, architectural design, earthquake code, torsion

*Assoc. Prof. Dr. Faculty of Architecture \& Design, Department of Architecture Konya Technical University, Konya, Turkey. ORCID E-mail: szkorkmaz@ktun.edu.tr 
to the projection ratio in plan. For non-orthogonal cases, structure with an inclined axis more than $30^{\circ}$, torsional irregularity factor exceeded the code-defined limit. Beneficial observations and conclusions were drawn for both architects and structural engineers' perspective.

\section{INTRODUCTION}

Chapter 3.6 of the recently published Turkish Building Earthquake Code TBEC (2018) addresses and describes the "Definition of Irregular Buildings". In this heading, the structures are classified as either regular or irregular (Korkmaz \& Korkmaz, 2013).

Geometric arrangements in plan and elevation view for various types of buildings are identified as irregularities. In TBEC 2018, architects are advised to design regular, symmetric structures (Tezcan \& Alhan, 2001). TBEC 2018 states that; "Regarding the definition of irregular buildings whose design and construction should be avoided because of their unfavorable seismic behavior". This is due to fact that structural irregularities affect the seismic performance of buildings (Inel, Ozmen, \& Bilgin, 2008). The code's main advice is to avoid these irregularities during the preliminary architectural design stage. It is known that irregularities in a structural system are influential in reducing the seismic performance of buildings (Mendi, 2005). Irregular configurations, either in plan or in elevation, was often recognized as the main cause of failure in past earthquakes, and the shape of a building might become a negative factor (Arslan, Korkmaz, \& Gulay, 2006).

In TBEC (2018), irregularities are defined under the two basic headings of irregularities in plan (denoted as A) and irregularities in elevation (denoted as B). Irregularities in plan are consistent with one of four different structural irregularity types: torsional irregularity, floor discontinuities, projections in plan, and nonparallel axes of structural elements (i.e., the configuration of structural elements on a nonparallel axis) (Ozmen \& Unay, 2007). There are also three types of structural irregularity in elevation (Figure 1). These types are defined under different sub-headings (Tugba Inan \& Korkmaz, 2011).

The code also defines the structural analysis assumptions required when such irregularities exist in a building (Mendi, 2005). Irregularity types $A 1$ and B2 govern the selection of a seismic analysis method. In buildings with irregularity types A2 and $A 3$, it must be verified that floor systems are capable to safely transfer seismic load between vertical structural elements (TBEC, 2018). In buildings with nonparallel structural element axes, the internal forces along the principal axes must be amplified. 


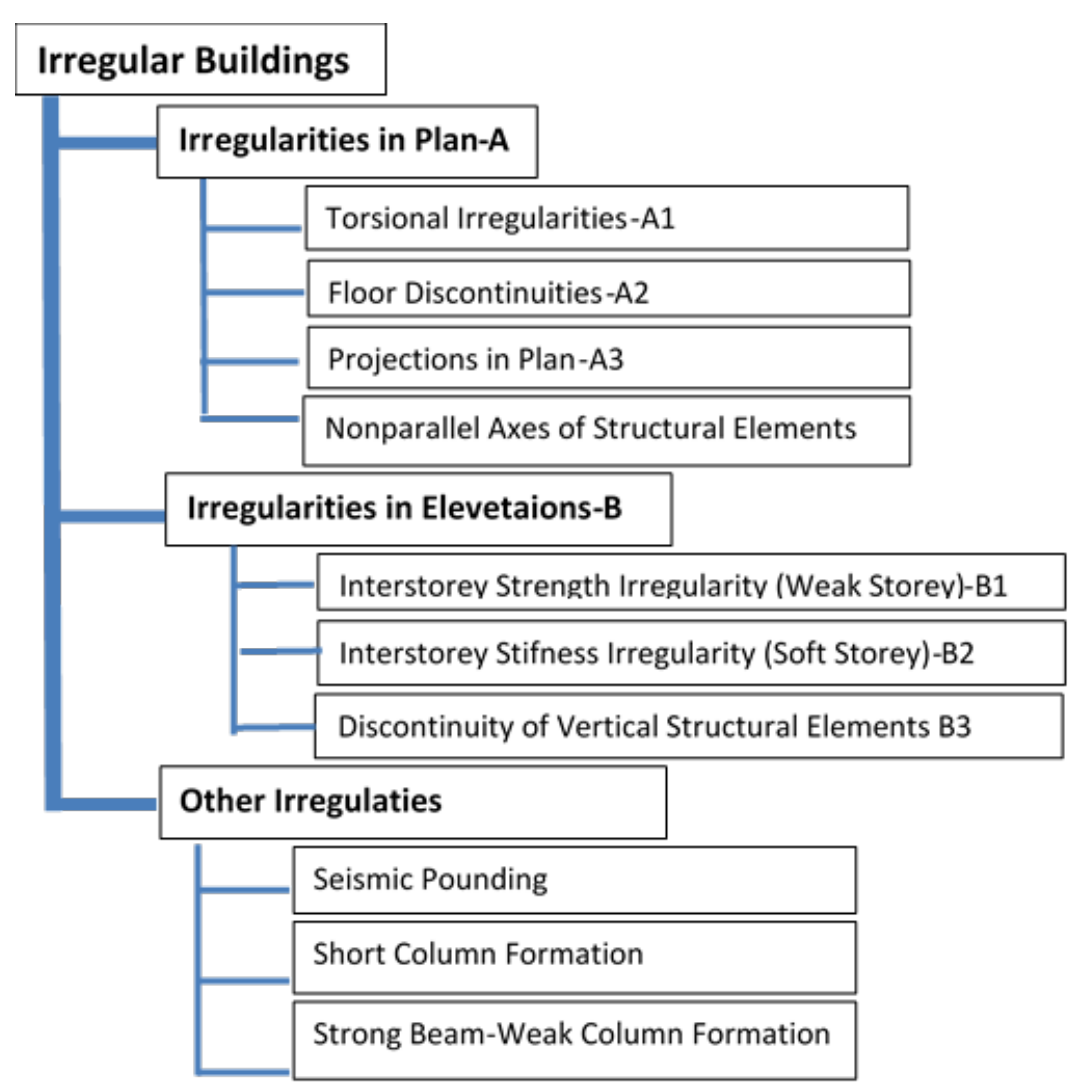

EVALUATION OF A STRUCTURE'S EARTHQUAKE RESPONSE

In seismic calculations, there are two orthogonal earthquake directions in a structure (X and $\mathrm{Y}$ ). The earthquake loadings are defined and FEA is conducted. After analysing the structure, the displacements of the top and bottom joints in the columns or shear walls are calculated $\left(\delta_{\mathrm{i}}\right)$ in the two orthogonal earthquake directions. The story drifts are calculated as the difference in the displacements between the two consecutive stories. For the $i^{\text {th }}$ story, $\Delta_{\mathrm{i}}$ can be calculated as

$\Delta \mathrm{l}=(\delta \mathrm{\imath})-(\delta \mathrm{t}-1)$

Story drifts are calculated by considering the effects of $\pm 5 \%$ additional eccentricities in both earthquake directions. The maximum $\left(\Delta_{\text {imax }}\right)$ and minimum $\left(\Delta_{\text {imin }}\right)$ story drifts were determined for the two orthogonal earthquake directions on each individual story of the building (Figure 2).
Figure 1. Irregularities defined in the Turkish Earthquake Code (TBEC 2018) 
Figure 2. Calculation of maximum and minimum story drifts

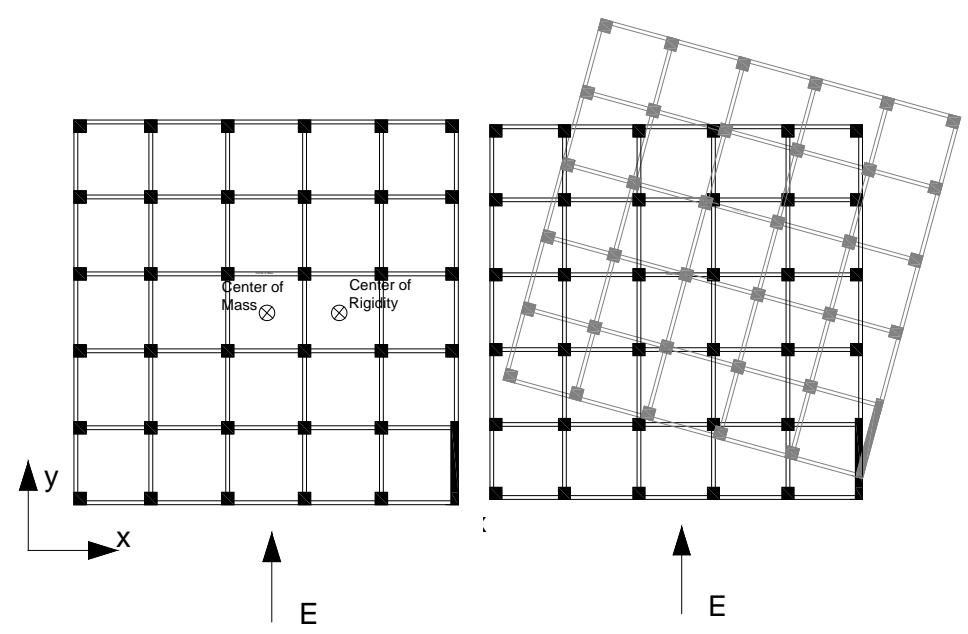

The average relative story drift of the ith story in either of the earthquake directions, which are orthogonal to each other, can be calculated as

$\Delta_{\mathrm{i}-\mathrm{ave}}=\left(\left(\Delta_{\text {imax }}\right)+\left(\Delta_{\text {imin }}\right)\right) / 2$

The torsional irregularity factor $\left(\eta_{\mathrm{bi}}\right)$ is defined as the ratio of the maximum story drift at any story to the average story drift at the same story in the same direction, and can be formulated as

$\eta_{\mathrm{bi}}=\left(\Delta_{\text {imax }}\right) /\left(\Delta_{\mathrm{i} \text {-ave }}\right)$

When a structure's torsional irregularity coefficient $\eta$ bi is greater than 1.2, torsional irregularity (type A1) is said to exist in that structure (TBEC, 2018). In a case where type A1 irregularity exists at any ith story such that the condition $1.2<\eta_{\mathrm{bi}}<2.0$ is satisfied, the $\pm 5 \%$ additional eccentricity defined above and applied to this floor must be amplified by multiplying it with coefficient $\left(D_{i}\right)$ (depending on the earthquake direction), which is called the amplification factor and can be formulated using Eq.4. The design eccentricity $\left(e_{d}\right)$ is now calculated from Eq. 5 and the analysis is repeated.

$\mathrm{D}_{\mathrm{i}}=\left(\eta_{\mathrm{bi}} / 1.2\right)^{2}$

$e_{d}=e+0.05 \times D_{i}$

Here, ed is the design eccentricity and e is the existing eccentricity of the structure. Although the code gives certain recommendations for assessing the degree of irregularity and corresponding penalties and restrictions, it is important to understand that these recommendations are meant as discouragement and to make the designer aware of irregularities' potential detrimental effects (Duggal, 2007). 
If $\eta_{\mathrm{bi}}$ is greater than 2 , the structural system is changed and reanalyzed. Most of the seismic codes, along with the TBEC-2018, define torsional irregularity as a significant irregularity because of the devastating effects documented for buildings with this irregularity after earthquakes (Gülay \& Çalım, 2003).

There are some restrictions on the utilization of the equivalent earthquake loading (EEL) method in structures where torsional irregularity exists. In general, the dynamic analysis is preferred as a safe method, for torsional irregular structures.

Earthquake loads act on a structure's center of gravity, but the structure's rigidity center responds to these loads. The distance between the center of gravity and center of rigidity should be at a minimum. If the eccentricity is large, a torsion moment will occur around the center of rigidity and creates additional shear forces in the columns. It is very difficult to change the location of the center of gravity. On the other hand, the center of rigidity can be modified by experimenting with cross-sections and the locations of columns and shear walls (Ozmen \& Unay, 2007). In other words, the center of gravity and the center of rigidity can coincide through regular disposition of the vertical structural members (Tugba Inan \& Korkmaz, 2011).

\section{PLAN GEOMETRY AND TORSIONAL IRREGULARIT}

The relationship between building plan geometries and torsional response was investigated using finite element models (FEM) of the selected structural systems. Cases involving projections in plan, and non-orthogonal axes of the system were evaluated within the study. The generated 3D models were analysed under lateral earthquake loadings. Obtained results were compared in terms of their earthquake behaviour.

Six different, 9-story structural models, including the reference building, were modelled to investigate the relationship between irregularities and the consequences of earthquakes. The reference structure was a typical moment-resisting, beam-column dominated RC (Reinforced Concrete) frame, which is the most common seismic framing system used for building construction in Turkey (Sezen, Elwood, Whittaker, \& Mosalam, 2003). The reference model's frame measured $25 \mathrm{~m}$ by $25 \mathrm{~m}$ in plan and had $5 @ 5 \mathrm{~m}$ bays in both the $\mathrm{X}$ and $\mathrm{Y}$ directions. The floor plans were identical in all storys. The first model, or reference model, did not contain irregularity and was named as "Regular Frame".

Three-dimensional mathematical models were created using the ETABS finite element program to carry out separate linear 
dynamic analyses in the longitudinal and transverse directions. The columns were designed to be square for simplicity.

The proper representation of building stock was the primary concern in the design and detailing of the model buildings. Because the majority of Turkish buildings were constructed according to the 1975 Turkish Earthquake Code, the selected model buildings were designed according to this code and considering vertical gravity loads (Inel M., Ozmen H.B., Bilgin H., 2008). The vertical loads consisted of live and dead slab loads, infill wall loads on beams and the dead loads of columns and beams. The total gravity load was calculated as 1.4 times the dead load (G) plus 1.6 times live load (Q). To prevent creep failure, the Turkish Reinforced Concrete Code (TS500, 2000) dictates that, the capacity of a column (Acxfck) must be at least twice that of the load calculated using the $1.4 \mathrm{G}+1.6 \mathrm{Q}$ load combination. Here, $\mathrm{G}$ is the dead load and $Q$ is the live load acting on the columns' tributary area. Note that the story weight consists of the dead load and $30 \%$ of the live load (for residential buildings according to TBEC (2018)) at the time of the earthquake.

A concrete strength of $20 \mathrm{MPa}$ was selected and the reinforcement ratio of the columns was set at $1.5 \%$. The uniform slab gravity loads were $2.5 \mathrm{kN} / \mathrm{m} 2$ for the dead load case and $3 \mathrm{kN} / \mathrm{m}^{2}$ for the live load case. The dead load of the infill walls was assigned as distributed loads on the beams. The thickness of the slab was 150 $\mathrm{mm}$ and the typical floor height was set at $3 \mathrm{~m}$. The beam crosssections were assumed to be T-shaped for the interior beams and L-shaped for the exterior beams. All beams had $250 \mathrm{~mm}$ crosssectional widths. The column and beam dimensions used in this study were typical frame element proportions present in the existing Turkish building stock. No effort was made to create a strong column-weak beam system because such systems were not considered in the 1975 version of the Turkish Earthquake Code. The building was assumed to have 5\% damping in all of its deformation modes (Inel et al., 2008; Munshi \& Ghosh, 1998; Tezcan \& Alhan, 2001).

Analyses were performed in the ETABS package program. This program is very similar to SAP2000 and has special advantages for building-type structures. This structural software was chosen because it represents a common platform between structural engineers and architects that enables collaborations (Inan, Korkmaz, \& Çağatay, 2012).

The columns were modelled with frame members, while the slabs were modelled with shell elements. Slabs were assumed to be 
infinitely rigid and rigid diaphragms were assigned. Foundations were not considered, and fixed supports were assumed at the base of each building. Seismic analyses were carried out in accordance with the recently published Turkish Earthquake Code TBEC (2018), which shows similarities to the FEMA-356 (2000) guidelines (Inel et al., 2008; Tezcan \& Alhan, 2001).

The model structures were assumed to be located İzmit city (located in the regions of high seismicity) and the importance factor, I, was set equal to 1.0 (for residential and office buildings). Structural behavior factor, $\mathrm{R}$, was set equal to 4 for reinforced concrete moment resisting frames of nominal ductility (Sezen et al., 2003).

\section{Buildings with Re-Entrant Corners and Projections}

Some structures contain projections in plan constituting reentrant corners due to the land dimensions, architectural considerations or functional necessities, or to animate buildings. Shapes such as H, L, T, U, Y, +, or a combination of these forms are typical examples of building configurations that contain projections or wings in plan. Such buildings are commonly designed for high-density housing and hotel projects because they enable large plan areas in compact forms, which have different vistas and lighting opportunities from different angles (Christopher Arnold, 1996). Buildings with projections have often been severely damaged during earthquakes (Figure 3) (Mendi, 2005; Wakabayashi, 1986).

The problem with projections in plan is explained by means of Figure 4. If several blocks meet, the structure becomes susceptible to EQ loads. The inside corners are called re-entrant corners and the connection point is called the notch point. If an earthquake comes from the $\mathrm{Y}$ direction as shown, the projection located parallel to the earthquake direction (block A) behaves more stiffly than the perpendicular projection (block B). Both projection blocks experience different displacements and push or pull each other at re-entrant corners or notch points. Critical stresses accumulate at the notch points where the projections connect. The magnitude of the accumulated stresses depends on the wing height, slenderness ratio, length and length ratio. A good example of damage in a re-entrant corner was observed in the 1999 Marmara Earthquake (Figure3). 
Figure 3. Damage in the re-entrant corner of an L-shaped building (source: Anonymous, 2000, Arslan and Korkmaz 2007)

Figure 4. Behaviour of an L-shaped structure with a projection.
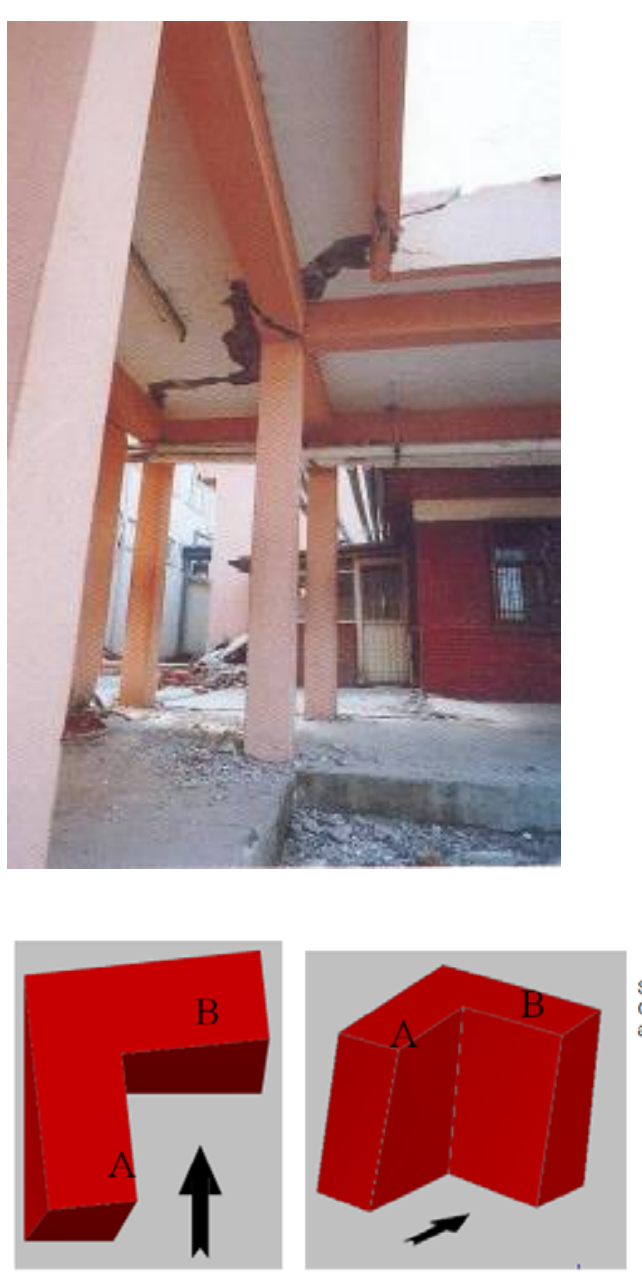

Stress Concentration
at the Notch

The other problems associated with projections can be summarized as follows.

- $\quad$ Because the center of mass and center of rigidity cannot geometrically coincide in this shape, they cause additional torsional stresses on the structure that are very difficult to analyze and predict (C Arnold, Reitherman, \& Whitaker, 1981).

- $\quad$ Long structural systems with an extended form in plan can experiences greater variations in soil conditions.

- $\quad$ The introduction of deep re-entrant angles into buildings introduces complexities into the analysis that makes them potentially less reliable than simple forms. Long wings cause problems in behavior prediction (Dowrick, 2009; Duggal, 2007; Mendi, 2005; Ozmen \& Unay, 2007).

- $\quad$ Plan configuration can be symmetrical, as illustrated in Figure 5, but become irregular due to re-entrant corners. $\mathrm{H}$ shapes, although symmetrical, should not be encouraged either. 
The horizontal shearing effect is a common problem due its occurrence in very short as well as tall buildings (Figure 6). The taller the structure, the greater the dimension of critical movement near the top will be (J. Ambrose \& Vergun, 1999).
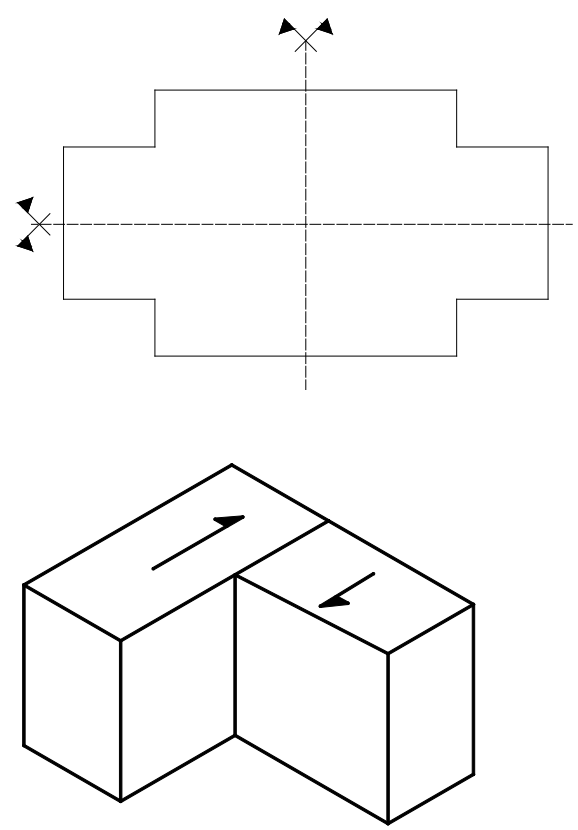

The TBEC (2018) highlights the fact that the ratio of projections to the entire plan is very important in terms of a building's seismic behavior. Plan irregularities related to projections are defined in TBEC (2018) under the heading for A3 type irregularities as the cases where the dimensions of projections in both perpendicular directions in plan exceed the total plan dimensions of that story of the building in the respective directions by more than $20 \%$. In buildings with irregularity type A3, it shall be verified by calculation in the first and second seismic zones that the floor systems are capable of safe transfer of seismic loads between vertical structural elements (Figure 7). In Figure 8 several structural layouts having projections in plan are given.
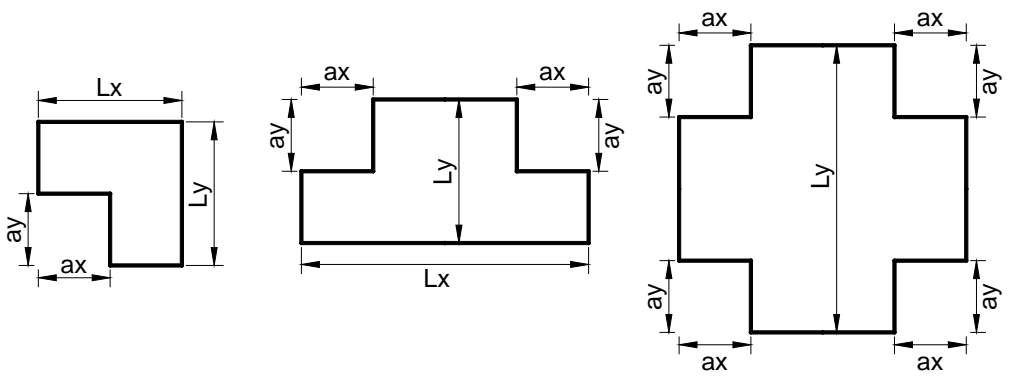

Figure 5. Plan geometry with symmetry but also irregularity
Figure 6. Horizontal shearing effects in projections in plan
Figure 7. A3 type irregularity (ax/Lx $>0.2$ and ay/Ly>0.2 at the same time) a)

b) c) 
According to TBEC (2018), for an A3 type irregularity to exist, the dimensions must satisfy $a_{x} / L_{x}>0.2$ and $a_{y} / L_{y}>0.2$ simultaneously. In Figure 7-a, the explanation is clear. If $\mathrm{L}_{\mathrm{x}}=10 \mathrm{~m}$, and $\mathrm{a}_{\mathrm{x}}=2 \mathrm{~m}$, then there is an A3 type irregularity. But in the case of Figure 7-b, $L_{x}$ must be $10 \mathrm{~m}$ and $\mathrm{a}_{\mathrm{x}}$ must be $2 \mathrm{~m}$ to form an A3 type irregularity. The total projection length becomes $4 \mathrm{~m}$ in the $\mathrm{X}$ direction.

The building in Figure 9 was analyzed to determine the critical projection ratio. The structure had the same plan area as that in the previous case, but this building had different projection ratios $\left(\mathrm{a}_{\mathrm{x}} / \mathrm{L}_{\mathrm{x}}\right)$. The projection lengths were determined to measure 2.5 $\mathrm{m}, 5 \mathrm{~m}, 10 \mathrm{~m}$ and $15 \mathrm{~m}$ in the $\mathrm{X}$ or $\mathrm{Y}$ directions. The span lengths or distances between columns were kept constant for all cases except for the 2.5 wing length cases. The dimensions of the columns in the wings were identical to the column dimensions in the main structure.
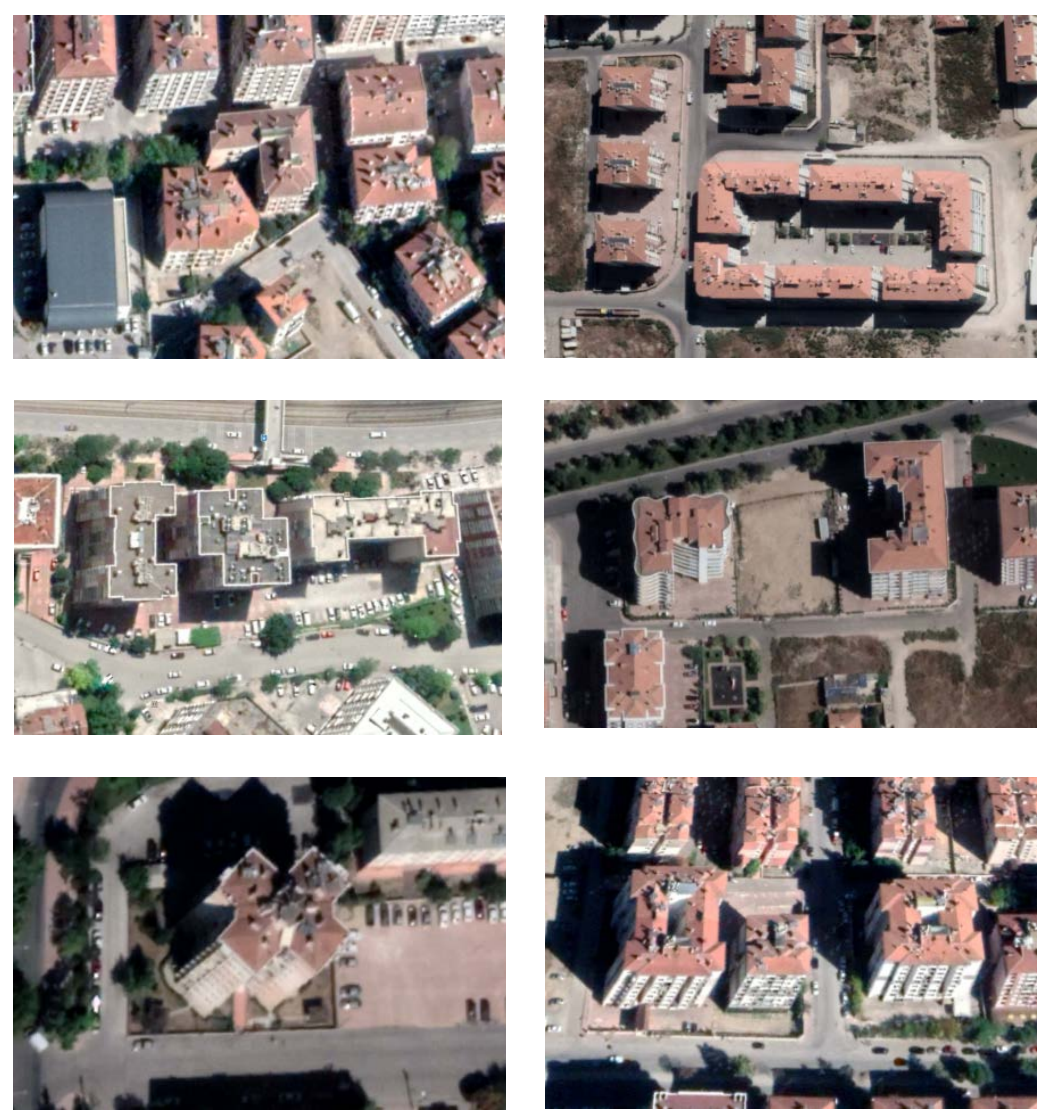

Figure 8. Several building layouts with projections in plan
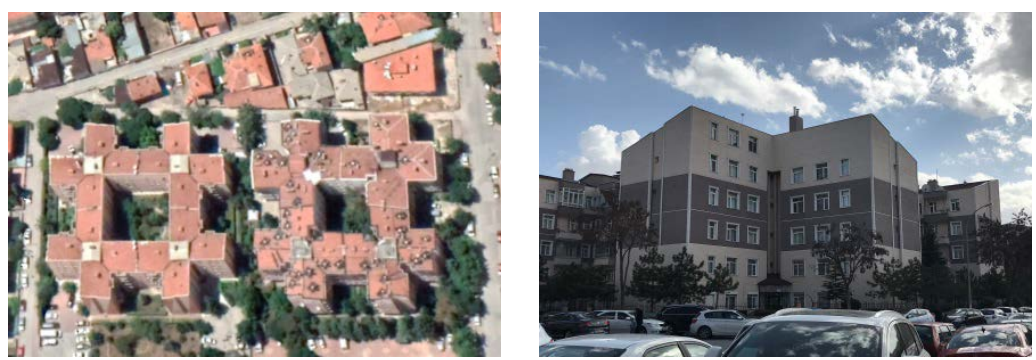
Representative illustrations of the analysis cases are depicted in Table 1 . The number of storys was chosen as a parameter and varied between 1 and 13 storys. The dimensions of the square columns were changed according to the number of storys. Except for the models in the first column (cases I, M, and R), an A3 type irregularity occurred because the projection ratios in both directions exceeded the limit ratio of $20 \%$.

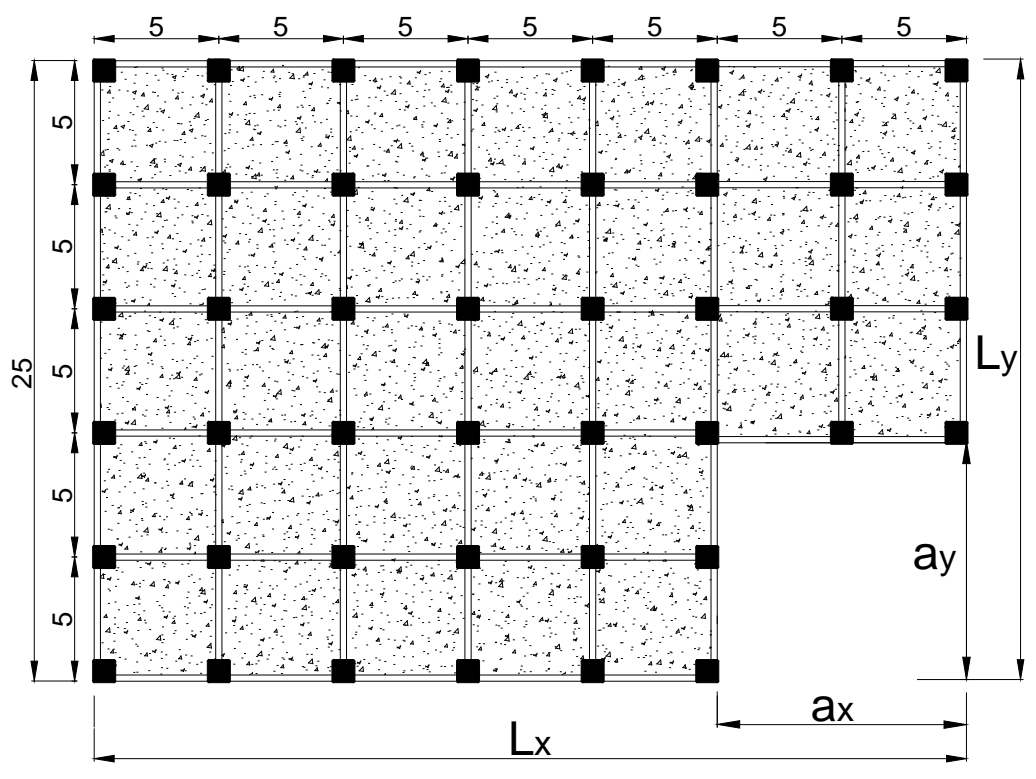

Figure 9. Model structure for projections in plan

Table 1. Analysis cases for projections in plan

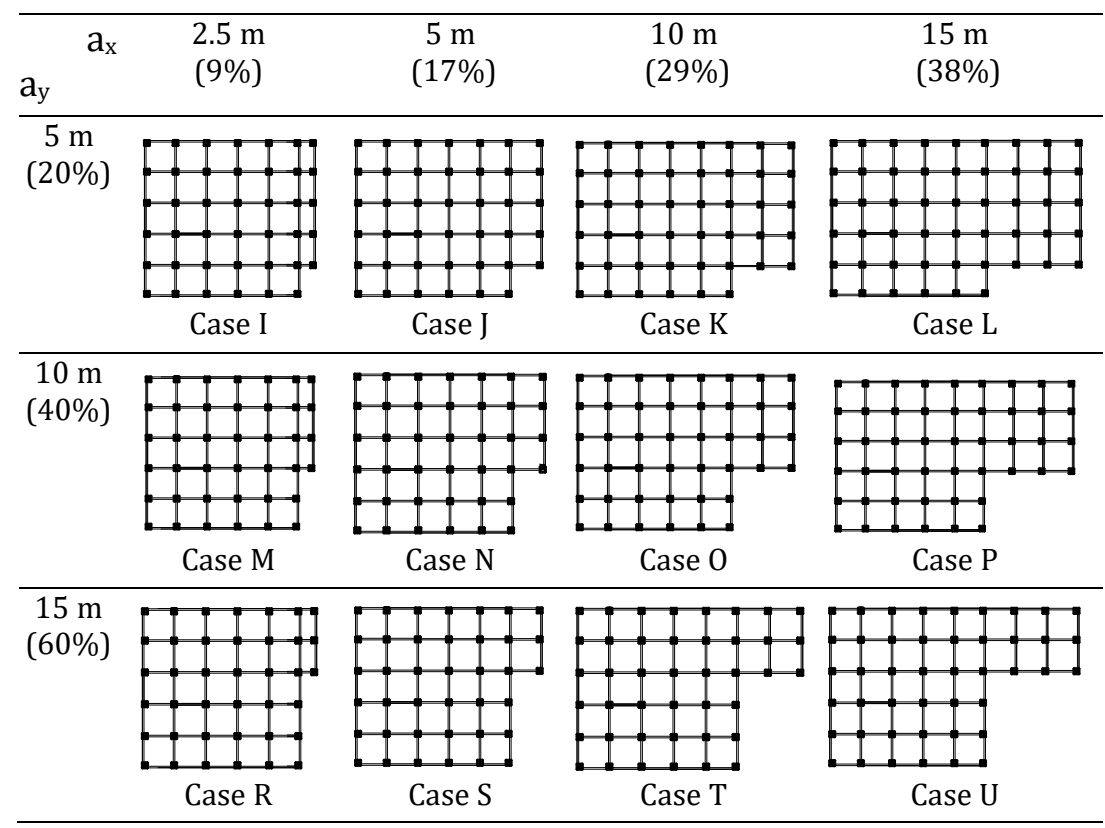

The models were analyzed considering two orthogonal earthquake directions separately to determine the drifts of their columns. The torsional irregularity factors were calculated by referring to the TBEC (2018) and are compared in Figure 10. 
For constant $\mathrm{a}_{\mathrm{y}}$ values, the torsional movements showed an increasing trend as the $a_{x}$ dimension increased (Figure $10 a-b-c$ ). The torsional irregularity coefficients were at a maximum for 1story cases and tended to decrease in 2-story cases. However, an increase became noticeable again as the number of stories increased after that. If the projection length in the $\mathrm{X}$ direction $\left(\mathrm{a}_{\mathrm{x}}\right)$ was equal to the $15 \mathrm{~m}$, the torsional irregularity factor was above the code limit of 1.2 for cases $a_{y}=15 \mathrm{~m}, 10 \mathrm{~m}$ and $5 \mathrm{~m}$.

In Figure 10-d-e and $\mathrm{f}$, the torsional irregularity factors are compared while keeping $\mathrm{a}_{\mathrm{x}}$ constant and taking $\mathrm{a}_{\mathrm{y}}$ as a parameter. In Figure 9-d, for a constant $a_{x}$ value of $15 \mathrm{~m}$ and models with up to 7 stories, the $\eta_{b i}$ value of the structures increased as $a_{y}$ decreased. But in models with a total number of storys greater than 7 , the $\eta_{\text {bi }}$ values increased as the $a_{y}$ value increased. The same observations were valid for the cases with $\mathrm{a}_{\mathrm{x}}=10 \mathrm{~m}$ and $\mathrm{a}_{\mathrm{y}}=15 \mathrm{~m}$, $10 \mathrm{~m}, 5 \mathrm{~m}$ as a parameter (Figure 10-e).

According to TBEC (2018), A3 type irregularities existed in the models for Cases L-P and $U$, and the corresponding $\eta_{b i}$ values were higher than the code limit (with A1 type irregularities observed). On the other hand, although A3 type irregularities existed in Cases $\mathrm{K}, \mathrm{O}$ and $\mathrm{T}$, the torsional irregularity factors were below the limit of 1.2 (there were no A1 type irregularities). There were no A3 type irregularities in the other models, which also had torsional irregularity factors below the limit value.

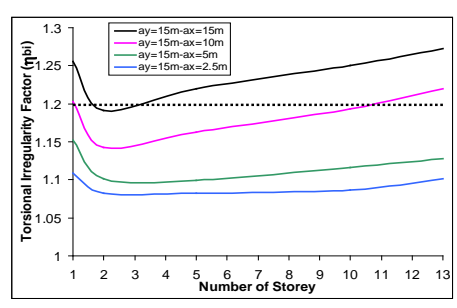

a)

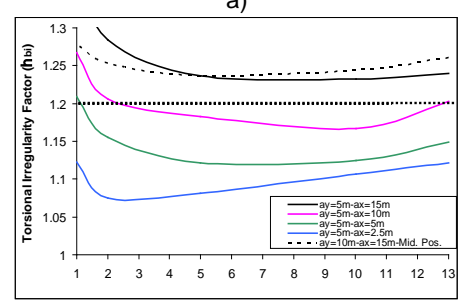

c)

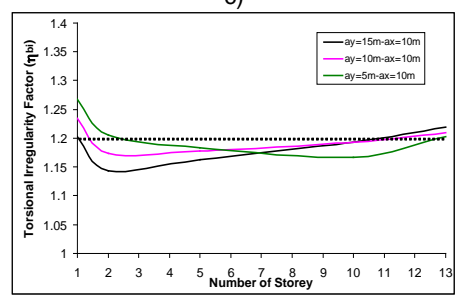

e)

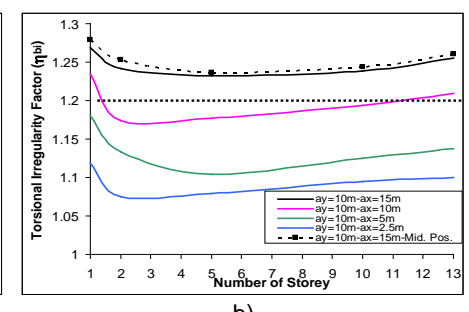

b)

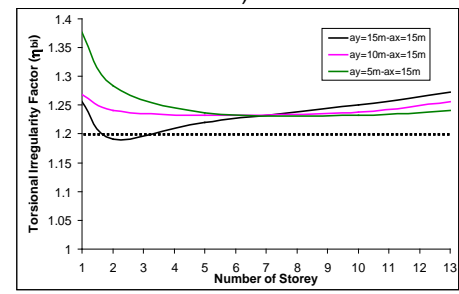

d)

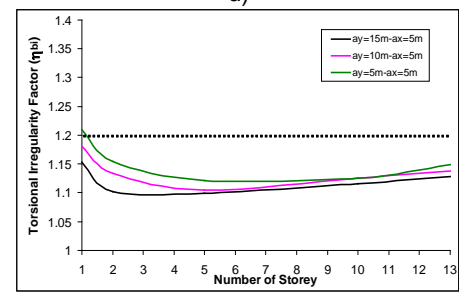

f)
Figure 10. Torsional irregularity factors $\left(\eta_{\mathrm{bi}}\right)$ for different projection ratios in plan 
The effect of wing configuration and location was also investigated (Figure 11.). The wing on the top right of the model was placed on the middle right of the structure (in plan). This case was run for only the $a_{y}=10 \mathrm{~m}$ and $a_{x}=15 \mathrm{~m}$ dimensions $\left(a_{y}=10 \mathrm{~m}\right.$, $a_{x}=15 \mathrm{~m}$, Mid. Pos.) and the corresponding $\eta_{b i}$ values were compared with those of the first configuration in Figure 10-b. There was no difference between these two configurations.

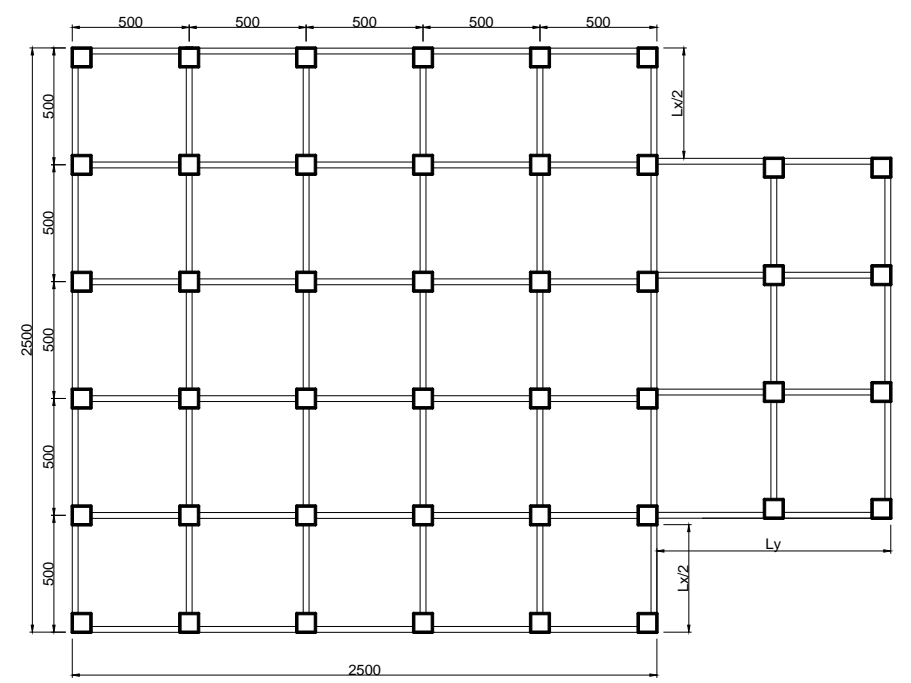

Figure 11. Effect of wing location

\section{Nonparallel Axes of Structural Elements}

Irregularities may exist in the configuration of a reinforced concrete structure if one or more of the columns or shear walls have an inclined axis with respect to the perpendicular earthquake directions. In the case of columns and shear walls with non-orthogonal placement, the principal axes of the vertical structural elements in plan are not parallel to the major orthogonal axes (Figure12). This type of irregularity is commonly seen as a result of:

- street intersections,

- space organization requirements in the design,

- taking advantage of the maximum parcel area, in line with owner requirements,

- abiding by the parcel form(Tugba Inan \& Korkmaz, 2011), or

- aesthetic requirements or animating the building facade. 
Figure 12. Non-orthogonal axis irregularity

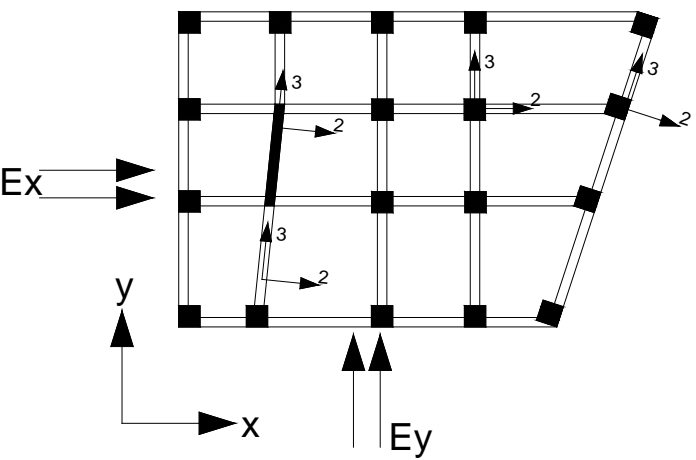

The structural problems related to non-orthogonal axes systems include:

- an overly complicated building structural analysis that requires a detailed three-dimensional dynamic analysis,

- difficulty in predicting lateral load distributions,

- exposure of structural elements to additional internal stresses in earthquake conditions, and overloaded beam connections under lateral earthquake loads.

Some building layouts with nonparallel axes are given in Figure 13.
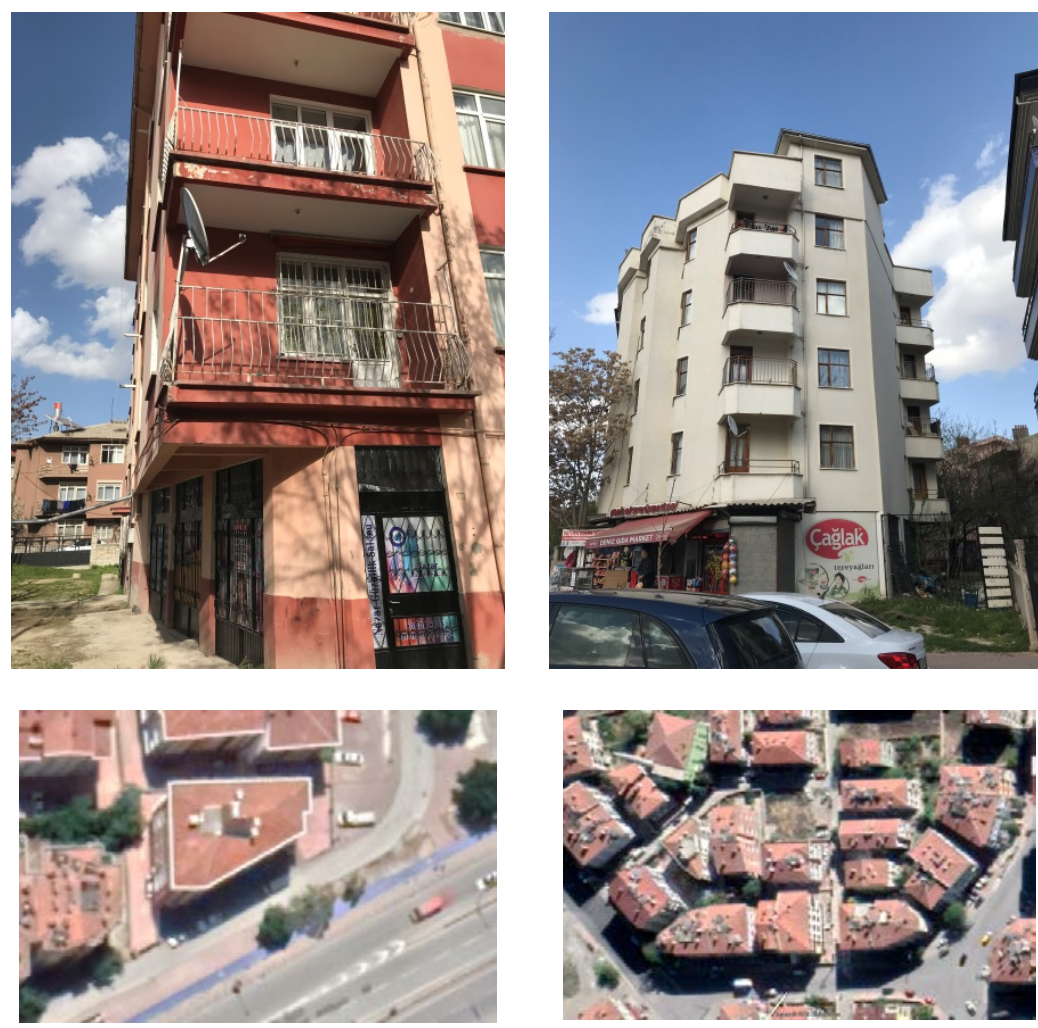
To investigate the effects of non-orthogonality on the distribution of moments and shears in vertical structural elements and torsional irregularity, a 9-story model building with one nonorthogonal and five orthogonal axes was studied (Figure 14). A dynamic analysis was performed to obtain the internal forces and base shear. A model building with 36 columns and 6 axes parallel to the both the $\mathrm{X}$ ( 1 to 6 ) and $\mathrm{Y}$ directions (A to F) was selected. All axes were orthogonal in the reference model, while only the $\mathrm{F}$ axis was non-orthogonal in the other models. Four cases with different non-orthogonal axis orientations were considered, and these orientations were altered by changing the angle $\alpha$ between the principal axis of the columns and the orthogonal $Y$-direction. The total area of the structure, dimensions of the columns and beams were kept constant in each model, while the angle $\alpha$ was varied to measure $0^{\circ}$ (reference model) $, 0^{\circ}, 5^{\circ}, 10^{\circ}, 20^{\circ}$ or $30^{\circ}$ measured in the counterclockwise direction. Each case was analyzed for four earthquake directions. For each $\alpha$ value, the direction of the earthquake was assumed to occur in four different directions: parallel to the $\mathrm{X}$-axis, parallel to the $Y$ axis of the structural system, parallel to the main principal axis and perpendicular to the main principal axis of the non-orthogonal columns.

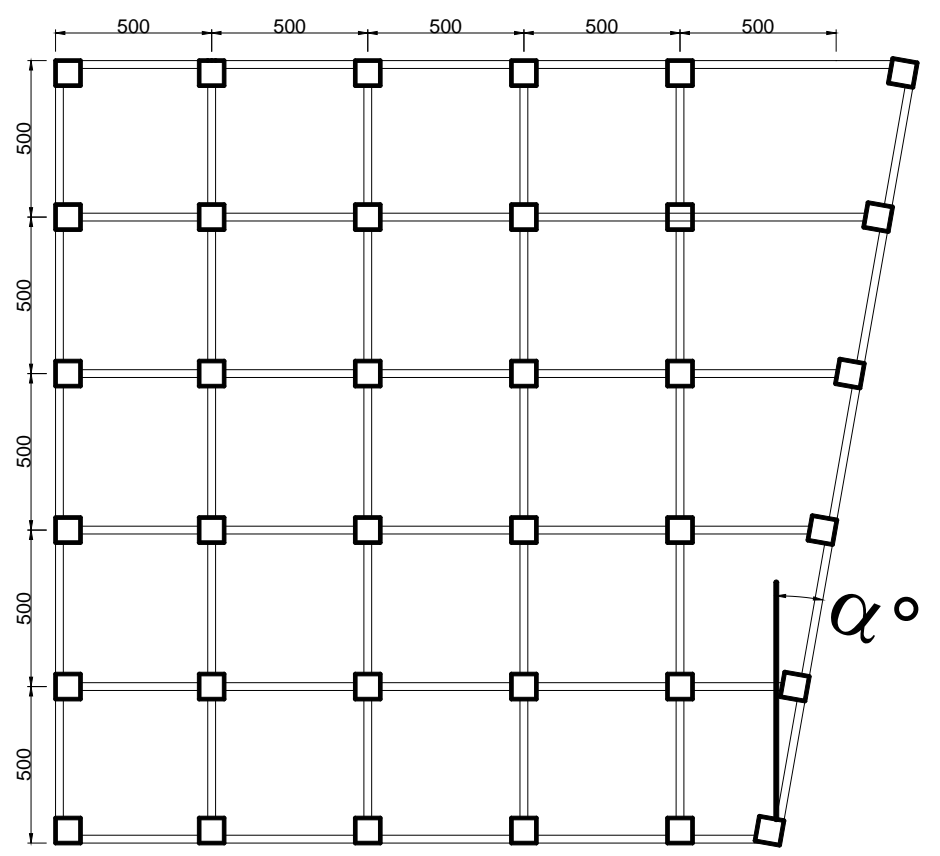

Figure 14. Non-orthogonal axes

The torsional irregularity factors were calculated from the relative point drifts of the columns and the results of which are illustrated comparatively in Figure 15 for $\alpha=0^{\circ}, 5^{\circ}, 10^{\circ}, 20^{\circ}, 30^{\circ}$. It is seen that, there was no clear difference between the 5 - and 10 -degree cases, while the $\eta_{\text {bi }}$ value of the 30 -degree case fell above the code limit of 1.2. 
Figure 15. Torsional irregularity factors for different axis angles

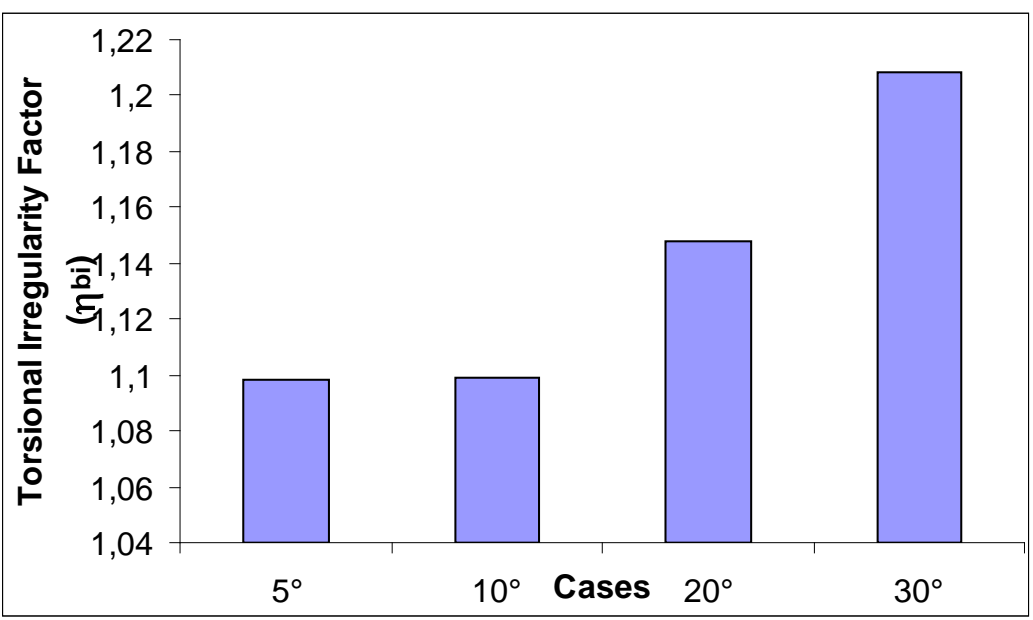

\section{Torsional Irregularity due to Structural Configuration}

Torsional irregularity generally exists on a structure due to its plan geometry. To prevent torsional deformation, a designer should provide symmetry in both the building's form and structure (J. E. Ambrose \& Vergun, 1985). However, the organization of structural members or a structural member's rigidity distribution may also create torsional irregularity. Sometimes, although a building whose form is a square or rectangle may be simple and symmetrical in plan, torsional forces can be created due to irregularities inside the building. A lack of symmetrical configuration in the columns or improper shear wall design may disturb the structure's symmetry and produce torsional effects, which are difficult to assess properly and can be destructive (Duggal, 2007; Mendi, 2005).

A school building in the Van city of Turkey (Figure 16), has a symmetrical rectangular plan. The structure had two parallel shear walls on its adjacent corners, creating an overly rigid side, and was torsionally balanced along the wall direction. In the other direction, however, the symmetry of the vertical members was disturbed. There were two separate parts, a flexible side and a stiff side, because the rigid walls were located on one side of the building. From the outside, the structure appeared regular. Unfortunately, the earthquake came from the weak direction. Torsion occurred around a vertical axis, leading to the building's destruction. The less rigid portion of the structure displayed more torsion than the rigid side. First, the school building twisted, and then farthest edge of corner columns failed and collapsed due to the torsional eccentricity. The concrete quality and details of the 
reinforcement arrangements were the other factors affecting the failure (Figure 17) (Korkmaz, 2015).
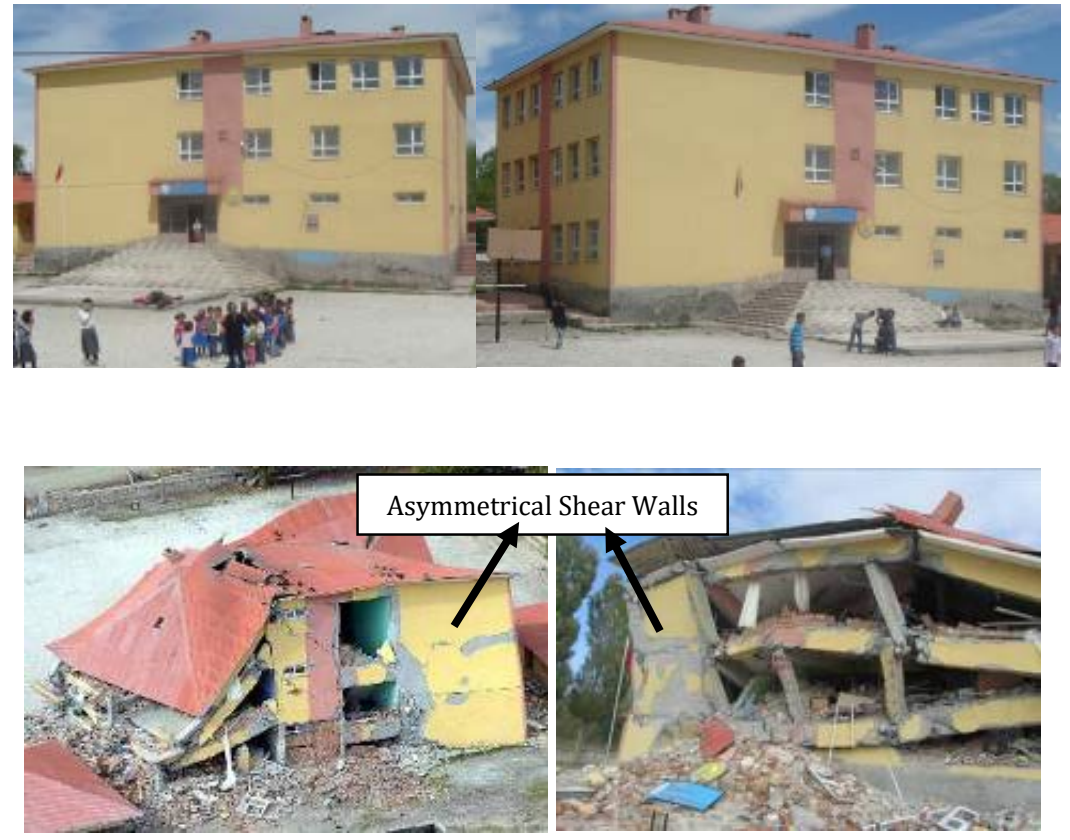

The location of shear walls should be chosen carefully, keeping in mind that the centers of gravity and rigidity are supposed to be as close together as possible. If the shear walls are concentrated on one side of the building, there will be excessive torsional eccentricity and uneven displacements in the structure (Ozmen \& Unay, 2007), and shear walls can be responsible for excessive damage during the earthquakes, as observed in the school building.

A typical building model was selected and analyzed to represent this theory. A sample building set was selected for reflection that included regular buildings both with and without shear walls and buildings with irregular shear wall configurations. The main reference structure was a typical moment-resisting beam-column $\mathrm{RC}$ frame with $25 \mathrm{~m}$ by $25 \mathrm{~m}$ in plan and identical to the regular structure in Section 3. It had 5@5 m bays in both directions. For the first two cases, the building plans were symmetrical in both the $\mathrm{X}$ and $\mathrm{Y}$ directions, while symmetry was maintained only in the $\mathrm{X}$ direction for the latter two cases.

The total number of storys was selected as a parameter and varied from 1 to 13. The first structural model did not contain any shear walls and was named the regular model case (Figure 18). In case A, two 5-m-long parallel shear walls were placed in the middle of the structure. Both the regular and Case A models were symmetrical in the $\mathrm{X}$ and $\mathrm{Y}$ directions. Torsional irregularity was created in the building by changing the locations of the shear
Figure 16. Gedikbulak Village school, Van, Turkey (source: http://okulweb.meb.gov.tr)

Figure 17. Primary school in Gedikbulak Village, after failure (source: https://fotogaleri.ntvmsnb c.com/helikopterden-depremalani.htlm?position=37) 
walls, shifting them to create three different cases of eccentricity, as shown in Figure 18. In Case B, two shear walls were shifted $5 \mathrm{~m}$ in the $\mathrm{X}$ direction, while in Case $\mathrm{C}$, the shear walls were shifted 10 $\mathrm{m}$ along the $\mathrm{X}$ direction. The modelling approaches for each case were similar to the assumptions given for Case D.

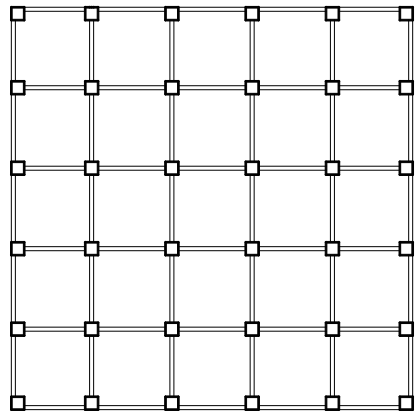

Regular

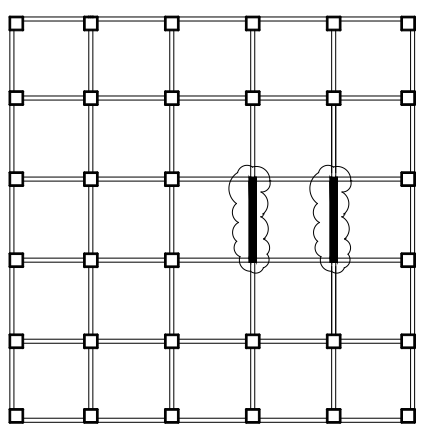

Case B

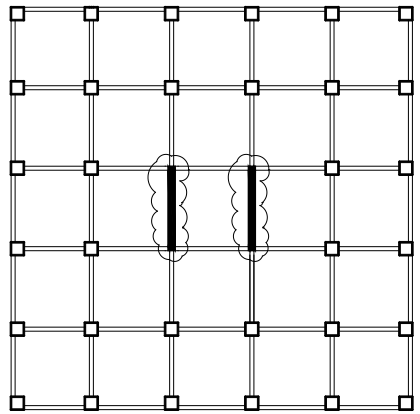

Case A

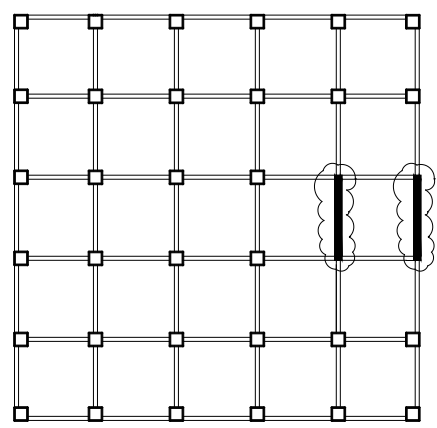

Case $\mathbf{C}$
Figure 18. Models for analyzing the effect of shear wall location
An additional accidental eccentricity of 5\% was applied even if the structure's existing eccentricity was zero, as dictated by TBEC2018. A dynamic analysis was carried out and the joint drifts were determined. Torsional irregularity factors were calculated for every floor and are tabulated in Table 2. The first column (1) in the Table represents the number of storys in the model, the second column (2) shows the initial additional eccentricity, $\eta_{\mathrm{bi}}-$ max, and the third column (3) shows the calculated maximum torsional irregularity factors after the first analysis run. When the $\eta_{\text {bi }}$-max value exceeded the TBEC-2018 limit value of 1.2 , the additional eccentricity of $5 \%$ was multiplied by an amplification factor $D_{i}$ (columns 4 and 5) and the model was reanalyzed. The new $\eta_{\mathrm{bi}}$-max values are listed in column 6. 
Table 2. Calculated eccentricity values

\begin{tabular}{|c|c|c|c|c|c|}
\hline \multicolumn{6}{|c|}{ Eccentricity Values - Case A } \\
\hline 1 & 2 & 3 & 4 & 5 & 6 \\
\hline \multicolumn{6}{|c|}{ Number of } \\
\hline 13 & 0,05 & 1,143 & - & - & - \\
\hline 10 & 0,05 & 1,143 & - & - & - \\
\hline 5 & 0,05 & 1,176 & - & - & - \\
\hline 3 & 0,05 & 1,198 & - & - & - \\
\hline 2 & 0,05 & 1,273 & 1,105 & 0,0552 & 1,333 \\
\hline 1 & 0,05 & 1,500 & 1,563 & 0,0781 & 1,600 \\
\hline \multicolumn{6}{|c|}{ Eccentricity Values - Case B } \\
\hline \multicolumn{6}{|c|}{ Number of } \\
\hline 13 & 0,05 & 1,36 & 1,12 & 0,056 & 1,36 \\
\hline 10 & 0,05 & 1,38 & 1,13 & 0,056 & 1,38 \\
\hline 5 & 0,05 & 1,53 & 1,37 & 0,068 & 1,55 \\
\hline 1 & 0,05 & 1,75 & 2,12 & 0,106 & 1,77 \\
\hline \multicolumn{6}{|c|}{ Eccentricity Values - Case C } \\
\hline $\begin{array}{l}\text { Numbe } \\
\text { Storys }\end{array}$ & $e x_{1} \%$ & $\eta_{b i}-\max$ & $D i$ & $D i * e x_{1} \%$ & $\eta_{b i}-2-\max$ \\
\hline 13 & 0,05 & 1,55 & 1,33 & 0,067 & 1,57 \\
\hline 12 & 0,05 & 1,55 & 1,35 & 0,067 & 1,57 \\
\hline 10 & 0,05 & 1,58 & 1,38 & 0,069 & 1,60 \\
\hline 7 & 0,05 & 1,65 & 1,55 & 0,077 & 1,67 \\
\hline 5 & 0,05 & 1,72 & 1,84 & 0,092 & 1,73 \\
\hline 3 & 0,05 & 1,77 & 2,12 & 0,106 & 1,78 \\
\hline 1 & 0,05 & 1,81 & 2,29 & 0,114 & 1,83 \\
\hline
\end{tabular}

Variations in the torsional irregularity factor with respect to the number of storys for cases B and C are given in Figure 19. The graphs clearly show that Case $\mathrm{C}$ had a higher torsional displacement than Case B. Calculated torsional irregularity factors were greater than 1.2. It was interesting to note that the $\eta$ bi values were higher in structures with 1 to 4 storys than in structures with 10 to 13 storys. The reason for this result could be attributed to the fact that, as the number of storys increased, the dimensions of the columns also increased. On the other hand, the lengths and thicknesses of the shear walls were kept constant. The influence of a shear wall on the lateral load carrying system decreased as the number of storys and column dimensions increased.

In Figure 20, the calculated maximum top story lateral displacements, under the orthogonal earthquake loadings, are plotted with respect to the number of storys. Cases B and C corresponded to the displacements with an additional eccentricity of 5\%, while the values for Cases B- 2 and C- 2 are calculated from the cases with additional eccentricities of (Dix $5 \%)$. Case $\mathrm{R}$ shows the displacements of the reference building with no shear walls. Symmetrically placed shear walls decreased 
Figure 19. Torsional irregularity factor with respect to the number of storys

Figure 20. Maximum lateral top displacements under orthogonal EQ loading cases the maximum lateral displacement. On the other hand, Case $\mathrm{C}$ (with 5\% additional eccentricity) displays values very close to those of Case R (with no shear wall). The shear wall configuration of Case $\mathrm{C}$ did not limit the lateral displacements but did cause torsion
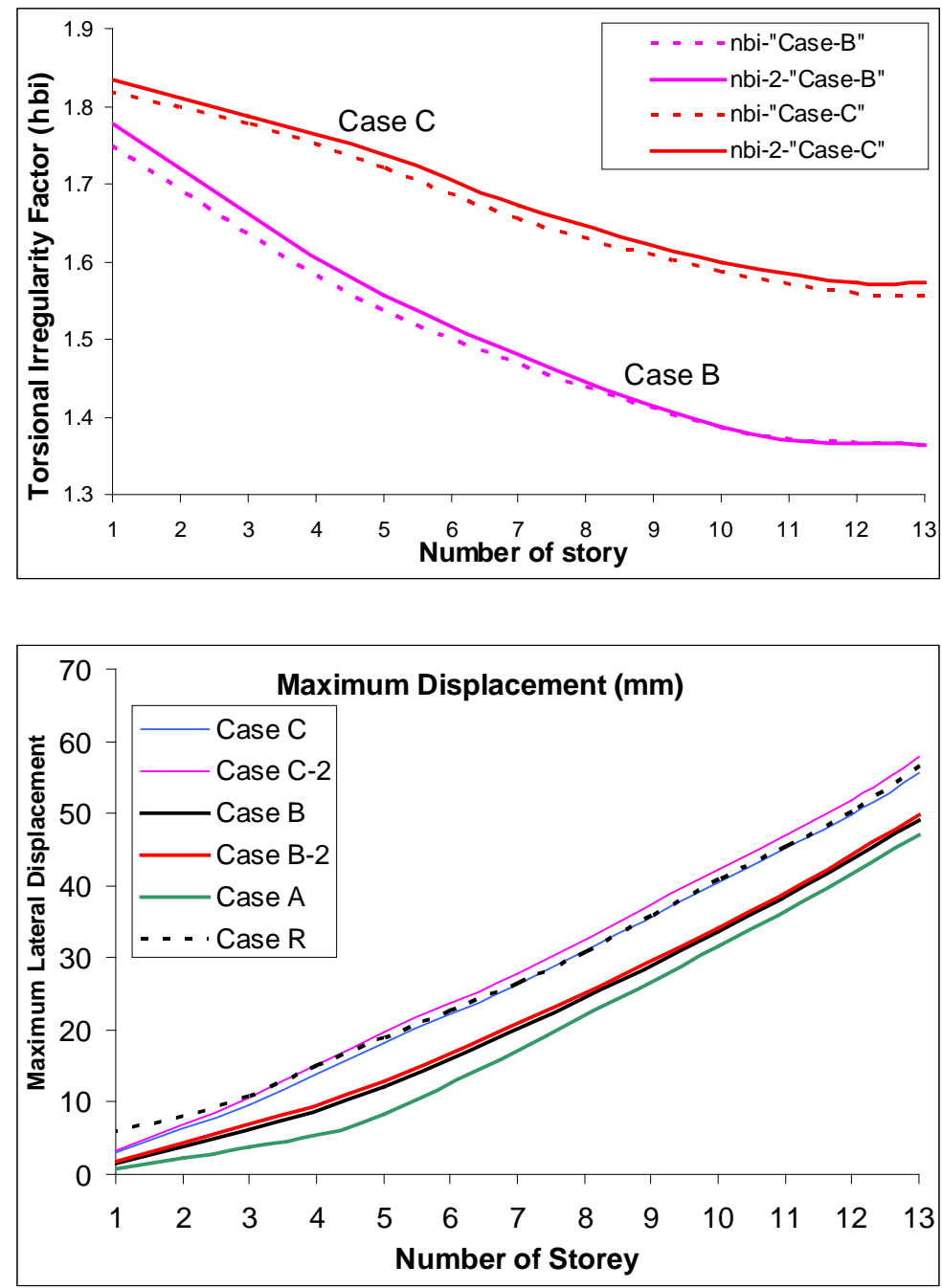

\section{CONCLUSIONS AND RECOMMENDATIONS}

The projections in plan (A3 type irregularity) and the ratio of projection as well as torsional response were analyzed in this study. The torsional rotation was found to be proportional to the projection ratio in plan. Although A3 type irregularities existed in models $\mathrm{K}, \mathrm{O}$ and $\mathrm{T}$, the torsional irregularity factors were below the code limit. On the other hand, when the projection ratios in the $\mathrm{X}$ direction were increased by $38 \%$, Cases $\mathrm{L}, \mathrm{P}$ and $\mathrm{U}$ displayed $\mathrm{A} 1$ type irregularities as well. The projection orientation (i.e., middle or side placement of the projection) had no significant effect on the torsional response. 
In this study, 4 model structures with non-orthogonal axes and one regular structure were analyzed. One of the external frames in each structure was inclined at angles of $5^{\circ}, 10^{\circ}, 20^{\circ}$ and $30^{\circ}$. From a torsional response viewpoint, the $5^{\circ}$ and $10^{\circ}$ cases showed no significant differences. In the $30^{\circ}$ case, however, the structure's torsional irregularity factor exceeded the code-defined limit and showed an A1 type irregularity.

The internal forces in the column at the intersection of the 5-F axes was evaluated. The calculated internal forces were divided by the corresponding value obtained in the regular case. At $20^{\circ}$ and $30^{\circ}$, the V3 and M2 internal forces or moments increased by approximately 1.18 times. This amplification remained limited in the V2 and M3 forces. On the other hand, at $5^{\circ}$ and $10^{\circ}$, all four internal force values were close to the values obtained in the regular case.

The torsional moment of column 5-F was also evaluated. In this case, the number of storys was also a parameter. The maximum amplification of the torsional moment was 3.5 times at $30^{\circ}, 2.5$ times at $20^{\circ}$ and below 2 at $5^{\circ}$ and $10^{\circ}$.

The last section of the study illustrated vertical structural element configurations and torsional responses. In Case A, the shear walls did not disturb the symmetry of the building and the lateral displacement decreased considerably. On the other hand, in Case $\mathrm{C}$, these shear walls were placed at the outermost sides of the structure and the symmetry along the $\mathrm{Y}$ axes no longer existed. The maximum lateral displacement of the structure was close to the case in which there were no shear walls. However, these asymmetrical shear walls disturbed the structure's torsional balance and the maximum torsional irregularity factor was found to lie between 1.9 and 1.6. The maximum torsional movement was obtained in low-rise structures because their column dimensions were smaller than those in high-rise buildings, and the shear walls thus became more governing for the behavior of the structure.

Linear elastic materials are assumed within the study, Cracked section properties may have effect on the results. Also more numerical analysis needs to be done to account for soft storys, short column effects and architectural design.

\section{REFERENCE}

Ambrose, J., \& Vergun, D. (1999). Design for Earthquakes. New York: John Wiley \& Sons, Inc.

Ambrose, J. E., \& Vergun, D. (1985). Seismic Design of Buildings. New York John Wiley \& Sons, Ltd. 
Anonymous. (2000). Earthquake Final Determinations, Special Publication. Retrieved from Bayindirlik Mudurlugu Turkey:

Arnold, C. (1996). Architectural aspects of seismic resistant design. Paper presented at the Eleventh World Conference on Earthquake Engineering, Mexico.

Arnold, C., Reitherman, R., \& Whitaker, D. (1981). Building Configuration And Seismic Design: The Architecture of Earthquake Resistance NASA STI/Recon Technical Report $N, 82$.

Arslan, M. H., \& Korkmaz, H. H. (2007). What is to be learned from damage and failure of reinforced concrete structures during recent earthquakes in Turkey? Engineering Failure Analysis, 14(1), 1-22. doi:10.1016/j.engfailanal.2006.01.0 03

Arslan, M. H., Korkmaz, H. H., \& Gulay, F. G. (2006). Damage And Failure Pattern Of Prefabricated Structures After Major Earthquakes In Turkey And Shortfalls of The Turkish Earthquake Code. Engineering Failure Analysis, 13(4), 537557. doi:10.1016/j.engfailanal.2005.02.006

Dowrick, D. J. (2009). Earthquake Resistant Design and Risk Reduction, 2nd Edition. New York: John Wiley \& Sons. Inc.

Duggal, S. K. (2007). Earthquake Resistant Design Of Structures. UK: Oxford University Press.

FEMA-356. (2000). Prestandard and commentary for seismic rehabilitation of buildings. In. Washington (DC): Federal Emergency Management Agency.

Gülay, F. G., \& Çalım, G. (2003). A Comparative Study of Torsionally Unbalanced Multi-Storey Structures under Seismic Loading Turkish Journal of Engineering And Environmental Sciences(27), 11-20.

Inan, T., \& Korkmaz, K. (2011). Evaluation Of Structural Irregularities Based On Architectural Design Considerations In Turkey. Structural Survey, 29(4), 303319.

Inan, T., Korkmaz, K., \& Çağatay, İ. H. (2012). An Investigation On Plan Geometries of Rc Buildings: With Or Without Projections In Plan. Computers and Concrete, 9(6), 439455.

Inel, M., Ozmen, H. B., \& Bilgin, H. (2008). Re-Evaluation Of Building Damage During Recent Earthquakes In Turkey. Engineering Structures, 30(2), 412-427. doi:10.1016/ j.engstruct. 2007.04.012

Korkmaz, S. Z. (2015). Observations on the Van Earthquake and Structural Failures. Journal of Performance of Constructed Facilities, 29(1), 0401403301-0401403325. doi:10.1061/ (ASCE)CF.1943-5509.0000456 
Korkmaz, S. Z., \& Korkmaz, H. H. (2013, 8-12 September, 2013). Seismic Design Considerations About Architectural Design Aspects And Irregularities. Paper presented at the Proceedings of the World Congress on Advances in Structural Engineering and Mechanics (ASEM13), Jeju, Korea.

Mendi, H. E. (2005). Evaluation Of Architectural Consciousness And Exploration Of Architecture-Based Issues In Seismic Design. (Master Dissertation), Middle East Technical University, Ankara, Turkey.

Munshi, J. A., \& Ghosh, S. K. (1998). Analyses Of Seismic Performance Of A Code Designed Reinforced Concrete Building. Engineering Structures, 20(7), 608-616.

Ozmen, C., \& Unay, A. İ. (2007). Commonly Encountered Seismic Design Faults Due To The Architectural Design Of Residential Buildings In Turkey. Building and Environment, 42(3), 1406-1416. doi:10.1016/j.buildenv.2 005.09.029

Sezen, H., Elwood, K. J., Whittaker, A., \& Mosalam, K. (2003). Performance of Reinforced Concrete Buildings During The August 17, 1999 Kocaeli, Turkey Earthquake, And Seismic Design And Construction Practise In Turkey. Engineering Structures, 25(1), 103-114. doi:10.1016/S01 41-0296(02)00121-9

TBEC. (2018). Turkish Building Earthquake Code. In. Ankara, Turkey: Ministry Of Public Works and Settlement.

Tezcan, S. S., \& Alhan, C. (2001). Parametric Analysis Of Irregular Structures Under Seismic Loading According To The New Turkish Earthquake Code. Engineering Structures, 23(6), 600-609. doi:10.1016/S0141-0296(00)00084-5

TS500. (2000). Turkish Standard-Requirements For Design And Construction of Reinforced Concrete Structures In. Ankara: Türk Standardlari Enstitüsü

Wakabayashi, M. (1986). Design Of Earthquake-Resistant Buildings. New York: McGraw-Hill.

Webpage. (2011). Primary school in Gedikbulak Village, after failure. Retrieved from https://fotogaleri.ntvmsnbc.com/ helikopterden-deprem-alani.htlm?position=37, 29 October 2011

Webpage. (2012). Gedikbulak village primary school. Retrieved from http://okulweb.meb.gov.tr, 19 December 2012.

\section{Resume}

Dr. Serra Zerrin Korkmaz graduated from Selçuk University, Department of Architecture in 1997. She completed her master's degree in 2001 and her doctorate in architecture in 2007. In her doctoral study, she worked on improving the earthquake 
performance of rural houses and received support from TUBITAK and the World Bank. In 2015, she became an associate professor in the department of building science. In general, the study area is related to the impact of architectural design on earthquake resistance of buildings. 